\title{
A Rare Case of Congenital Diaphragmatic Hernia with Meconium Pseudocyst
}

\author{
Nikhil Bansal* \\ Gaba Hospital, Yamuna Nagar, Haryana \\ *Corresponding Author: Nikhil Bansal, Gaba Hospital, Yamuna Nagar, Haryana
}

Received: May 27, 2019; Published: August 13, 2019

\begin{abstract}
Congential diaphragmatic hernia $(\mathrm{CDH})$ has an incidence of 1-6 per 10,000 live births1. Infants with congenital diaphragmatic hernia ( $\mathrm{CDH}$ ) have an increased incidence of associated malformations like craniofacial abnormalities, skeletal defects, cardiac defects, Ileal, atresia, volvulus, or malrotation of gut but not meconium pseudocyst2.
\end{abstract}

Keywords: Meconium Pseudocyst; Congenital Diaphragmatic Hernia

- Meconium peritonitis caused by meconium extruding into the peritoneal cavity through a small bowel perforation in utero. The estimated prevalence is about 1 per 35,000 live births and the mortality ranges from $11 \%$ to $50 \% 3$. Meconium peritonitis with pseudo cyst formation is rare and can be lethal.

- Meconium pseudocyst has not yet been previously described in asscociation with $\mathrm{CDH}$. This report describes the rare case of a meconium pseudocyst, with congenital diaphragmatic Hernia (left side). We believe this is a first case in literature with combination of two defects in a same child.

\section{Introduction}

- Congential diaphragmatic hernia (CDH) has an incidence of 1-6 per 10,000 live births [1]. Infants with congenital diaphragmatic hernia ( $\mathrm{CDH}$ ) have an increased incidence of associated malformations like craniofacial abnormalities, skeletal defects, cardiac defects, Ileal, atresia, volvulus, or malrotation of gut but not meconium pseudocyst [2].

- Meconium peritonitis caused by meconium extruding into the peritoneal cavity through a small bowel perforation in utero. The estimated prevalence is about 1 per 35,000 live births and the mortality ranges from $11 \%$ to
$50 \%$ [3]. Meconium peritonitis with pseudo cyst formation is rare and can be lethal. Meconium pseudocyst has not yet been previously described in asscociation with $\mathrm{CDH}$. This report describes the rare case of a meconium pseudocyst, with congenital diaphragmatic Hernia (left side).

\section{Case report}

- A 40 days old male child presented to us as a case of respiratory failure with shock. Child was immediately admitted in PICU and put on ventilator. Shock was managed. It was a full term vaginal delievery with history of birth Asphyxia for which child was admitted at some NICU for first 20 days of life and from there shifted to some other centre in view of persistent resp. distress, sepsis, abdominal distension, seizures and recurrent vomiting. Chest Xray taken twice during previous hospitalization and was misinterpreted as pneumonia and treated accordingly. For abdominal distension USG was done and suggestive of cystic lesion in left quadrant of stomach. In view of deteriorating clinical condition child was referred to us.

- On examination child weight $3 \mathrm{~kg}$. He was tachypneic with resp. rate of $100 / \mathrm{min}$ with severe intercostal and subcostal retractions, CFT $5 \mathrm{sec}$. There was decreased air entry on left side. X-ray chest done and suggestive of left $\mathrm{CDH}$. Abdominal examination show palpable mass in left lower quadrant. After stabilization of child emergency surgery was done.

Citation: Nikhil Bansal. “A Rare Case of Congenital Diaphragmatic Hernia with Meconium Pseudocyst”. Acta Scientific Paediatrics 2.9 (2019): 14-15. 
- $\quad$ At operative exploration, a large cyst was found intraperitoneally containing approximately $100-150 \mathrm{ml}$ of meconium. The cyst was completely resected and sample send for histopathology and biopsy and meconium pseudocyst was diagnosed. Careful examination of the intra abdominal viscera showed no evidence of intestinal perforation. CDH was repaired. The patient had an uneventful postoperative course. Child remained on ventilator for next 3 days and successfully discharged after 15 days of hospitalization.

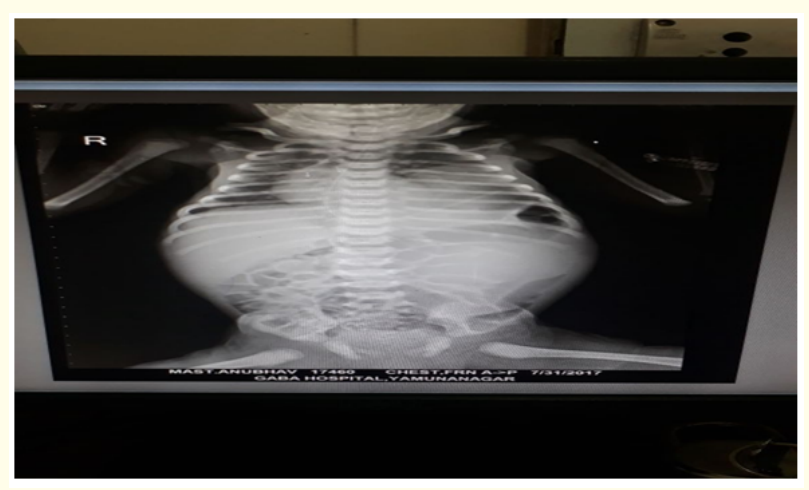

Figure

\section{Discussion}

- $\quad$ Although neonatal care has improved over the past 20 years, $\mathbf{C D H}$ remains as an anomaly with a high mortality rate [4]. This is not only due to the defect itself but also a combination of associated anomalies. Cardiovascular malformations and neural tube defects have a predominance among these anomalies [5]. The rate of gastrointestinal disorders remains low.

- Meconium peritonitis was first described by Morgagni in 1761 and more comprehensively by Simpson in 1838 .

- Meconium pseudocysts are commonly associated with meconium peritonitis, the estimated incidence of which is about 1 in 35,000 live births. It is a serious and potentially fatal neonatal condition that occurs secondary to fetal bowel perforation [6].

- Due to the low incidence of both we had little suspicion for their coexistence in the same patient. It is our belief that this may be the first report of its kind in the literature.

\section{Conclusion}

Meconium pseudo cyst is rare entity but can be confused with abdominal cyst due to other causes and gastric outlet obstruction.

\section{Bibliography}

1. B Mallikarjunappa and SR Ashish. "Department of Radiodiagnosis, Adichunchanagiri Institute of Medical Sciences, Nagamangala, Karnataka, India". Congenital Diaphragmatic Hernia: A Case Report JIMSA 25.4 (2012): 247.

2. Al-Faraaz Kassam., et al. "Newborn male presented with congenital diaphragmatic hernia and ileal atresia: A case report". Journal of Pediatric Surgery Case Reports 3.10 (2015): 444-446.

3. Eckoldt F., et al. "Meconium peritonitis and pseudo-cyst formation: prenatal diagnosis and post-natal course". Prenatal Diagnosis 23.11 (2003): 904-908.

4. Kaiser JR and Rosenfeld CR. "A populationbased study of congenital diaphragmatic hernia: Impact of associated anomalies and preopertive blood gases on survival". Journal of pediatric surgery 34.8 (1999): 1196-1202.

5. Langer CL and Harrison MR. In: Puri P(ed) Newborn Surgery, Butterworth, Heinemann, Oxford, (1995): 209-216.

6. Forouhar F Meconium peritonitis. "Congenital diaphragmatic hernia and evantration of the diaphragm". American Journal of Clinical Pathology 78 (1982): 208-213.

\section{Volume 2 Issue 9 September 2019}

(C) All rights are reserved by Nikhil Bansal. 